\title{
Empirical Model to estimate the Electricity Consumption of the Polymer Material Injection Molding Manufacturing Process
}

\author{
Ana Elduque ${ }^{1}$, Daniel Elduque ${ }^{2, *}$, Isabel Clavería ${ }^{2}$ and Carlos Javierre ${ }^{2}$ \\ 1 BSH Electrodomésticos España S. A., Avda. de la Industria, 49, Zaragoza, Spain (50016); \\ anaelduque@gmail.com \\ 2 i+, Department of Mechanical Engineering, EINA; University of Zaragoza, C/ María de Luna, 3, Zaragoza, \\ Spain (50018); delduque@unizar.es ; iclaver@unizar.es; carlos.javierre@unizar.es \\ * Correspondence: delduque@unizar.es; Tel.: +34-87-655-521
}

Received: 10 April 2018; Accepted: 23 May 2018; Published: 23 May 2018

\begin{abstract}
Polymer injection moulding is one of the most used manufacturing processes in the industry. Material and electricity consumption are two of the main points when analyzing the cost and also the environmental impact of these manufacturing processes. Reducing both cost and environmental impact of materials and manufacturing processes is one of the key challenges that material science and engineering face today to be more sustainable. In the case of the polymer injection moulding manufacturing process, reducing its electricity consumption is key to achieve a more sustainable manufacturing process. However, a lack of data regarding real electrical consumption values, and how to estimate them has been found. In this paper, a model to estimate the electric consumption of the injecting molding manufacturing process is proposed. This consumption estimation is obtained by means of a parametric model which was created after monitoring the electricity consumption of a wide range of injected parts. By applying this empirical model a better assessment of the electricity consumption, and also the environmental impact of the process can be achieved. This model can be of great interest for manufacturing process engineers, Life Cycle Assessment practitioners and also the industry, as it provides a method to estimate the electricity consumption and cost of an injected part depending on its characteristics and the selected injection machine.
\end{abstract}

Keywords: polymer material; manufacturing processes; electricity consumption, environmental impact, empirical model

PACS: J0101

\section{Introduction}

Climate change is forcing companies to perform risk management and also to look for opportunities in the path of reducing the environmental impact of their activities [1-2]. The European Union has created several laws devoted to the protection of the environment. Some of the key actions are reducing the generated waste [3] or promoting the eco-design of products, especially for those with significant energy consumptions [4].

The concern regarding the achievement of a sustainable development is also patent in the literature. Strategies to achieve a cleaner industrial sector are discussed by using, for example, analytical tools that help in the decision making of an industrial process [5], or linking lean manufacturing practices with the lifecycle assessment methodology in order to obtain a reduction of the environmental impact [6].

Life Cycle Assessment (LCA) is a methodology that allows scientist and engineers to quantify the environmental impact of products, processes or services. ISO standards 14040 [7] and 14044 [8] 
provide the principles, framework, requirements and guidelines to properly carry out a LCA. Using those LCA standards, initiatives like the CO2PE! have analyzed the environmental footprint and energy consumption of manufacturing processes [9-13], as energy consumption is key to assess the environmental impact of a production process.

Polymers are currently key materials in many industrial sectors and are used for applications such as packaging, building and construction, automotive, electrical and electronic appliances, etc. Polymer injection moulding is a common manufacturing process with high volumes in the industry [14]. Reduction of its environmental impact would be an important step to achieve a more sustainable development.

As discussed in previous work made by the authors, the electricity consumption of the injection molding process is the main factor in the total environmental impact of this process $[15,16]$. Due to this, achieving a reduction of the electricity consumption not only affects directly to the environmental footprint but also to the economic cost.

Therefore, injection molding producers should have as a goal to have a deeply knowledge of their machines in order to be able to optimize their consumption, obtaining at the same time these two important benefits. LCA studies have been performed to very different products and processes in all work fields, to assess its environmental impact [17-23]. Increasing the knowledge about the injection molding process leads to an improvement also in the LCA field, as databases, such as EcoInvent, that are used in the Life Cycle Inventory phase, are key in the results obtained in LCA studies.

EcoInvent's dataset injection molding process is created calculating the average of three processes: PVC, PP and PET, and consider for the environmental impact assessment, in addition to electricity consumption $(1,47 \mathrm{kWh} / \mathrm{kg}$ as mean value), consumption of water, lubricating oils, chemicals, fillers, solvents, packaging materials, natural gas for the factory, generated waste...etc. [24]. EcoInvent's injection dataset is based on reports from the European Plastics Industry called Plastics Europe [25,26], and from the Buwal database [27]. As previously explained, the highest contribution to the environmental impact of injection moulding is caused by the electricity consumption $[15,16]$. The analysis of EcoInvent's dataset sources show electricity consumption values from 1 to $2.1 \mathrm{kWh}$ per $\mathrm{kg}$ of injected plastic. Thera are also other contributions, that generate environmental impact, but several are not directly related to the injection process, such as gas natural used for heating or the packaging materials used for the manufactured parts; and also others that are only used for the injection of specific plastics like PVC (solvents and stabilizers) [15]. Focusing on the electricity consumption, previous research made by the authors shows that, for the same material, the specific energy consumption (SEC) varies from 0.43 to $2.3 \mathrm{kWh} / \mathrm{kg}$ [16]. Due to these wide ranges, LCA results for the injection moulding process can also differ substantially.

Not so many studies with experimental data of injection molding and its electricity consumption can be found yet in the literature. An interesting study of monitoring energy was published by Mianehrow and Abbasian [28] where they analyzed how different factors such as machine technology, or process related parameters affect the electricity consumption, being the cycle time and throughput one of the most important. More studies have been published in the recent years regarding the environmental impact of the injection molding process. Thiriez reviewed the complete process including the compounding of the raw material. In this research it is indicated that the type of injection molding machine has a great impact in the electricity consumption of the process [29]. Other authors focused their research in the environmental performance of biodegradable polymers $[30,31]$. Studies concerning the estimation of the electricity consumption of the injection molding process have been carried out using a theoretical approach instead of experimental, like the one used in this paper [32,33]. Spiering et al. remarked the importance of analyzing deeply the life cycle inventories also in the manufacturing processes [34]. Some researchers have focused on extrusion, another well-known polymer manufacturing process. Abeykoon et al. analyzed polymer extrusion energy consumption at different processing conditions, concluding that lower SEC values were usually obtained for higher throughput production processes [35,36]. 
In this research work, results from experimental measurements have been analyzed in order to define a parametric model that allows to estimate the electricity consumption of an specific injection molding process. By means of this empirical model a more precise value can be obtained to further assess the environmental impact and also the cost related to this manufacturing process.

\section{Materials and Methods}

As the purpose of this paper was to obtained a mathematical model, only a calculation sheet has been used to analyze the experimental data. Many tendencies have been observed and studied. As indicated by the authors in the paper "Influence of Material and Injection Molding Machine's Selection on the Electricity Consumption and Environmental of the Injection Molding Process: An Experimental Approach" [37], several conclusions can be drawn from the 36 experimental measurements.

One of the most important tendencies is that the more throughput $(\mathrm{kg} / \mathrm{h})$ the process has, the less SEC is obtained by the injected part. On the other hand, each injection molding machine shows a different tendency, as their technology and efficiency are different.

Twelve different injection molding machines were analyzed in these measurements: from a 2002 all-electric injection machine, with a clamping force of 85 tonnes, to the largest injection molding machine (8000 tonnes of clamping force).

\subsection{Parameters}

The parameters that have been selected to build this empirical model are the following:

- Percentage of the machine's utilization: relation between part injected volume and maximum volume that can be injected in one shot

- Machine's efficiency

- Throughput $(\mathrm{kg} / \mathrm{h})$

- Polymer material (Specific heat $[\mathrm{KJ} / \mathrm{kg} . \mathrm{K}] \times \Delta \mathrm{T}$ )

With these four parameters it is being included the influence of injection molding machine (its technology), how well it is the machine and process optimized and the properties of the polymer material.

A total of 36 measurements were used using different thermoplastics such as high density polyethylene, polypropylene, polycarbonate, polyamide with several percentages of fillers, etc. Further details regarding parts injected and measurement equipment to obtain real consumption values can be consulted in previous published work by the authors [37].

\section{Results and Discussion}

In the following section it is going to be explained how the empirical model is built, and the obtained results.

\subsection{Empirical Model}

Two steps were performed to adjust the empirical model. First electricity consumption was modeled considering the percentage of utilization and machine's efficiency. Figure 1 shows all experimental measurements in blue dots used for creating the empirical model. The low, medium and high efficiency lines, show the limits of the SEC depending on the efficiency of the injection machine. 


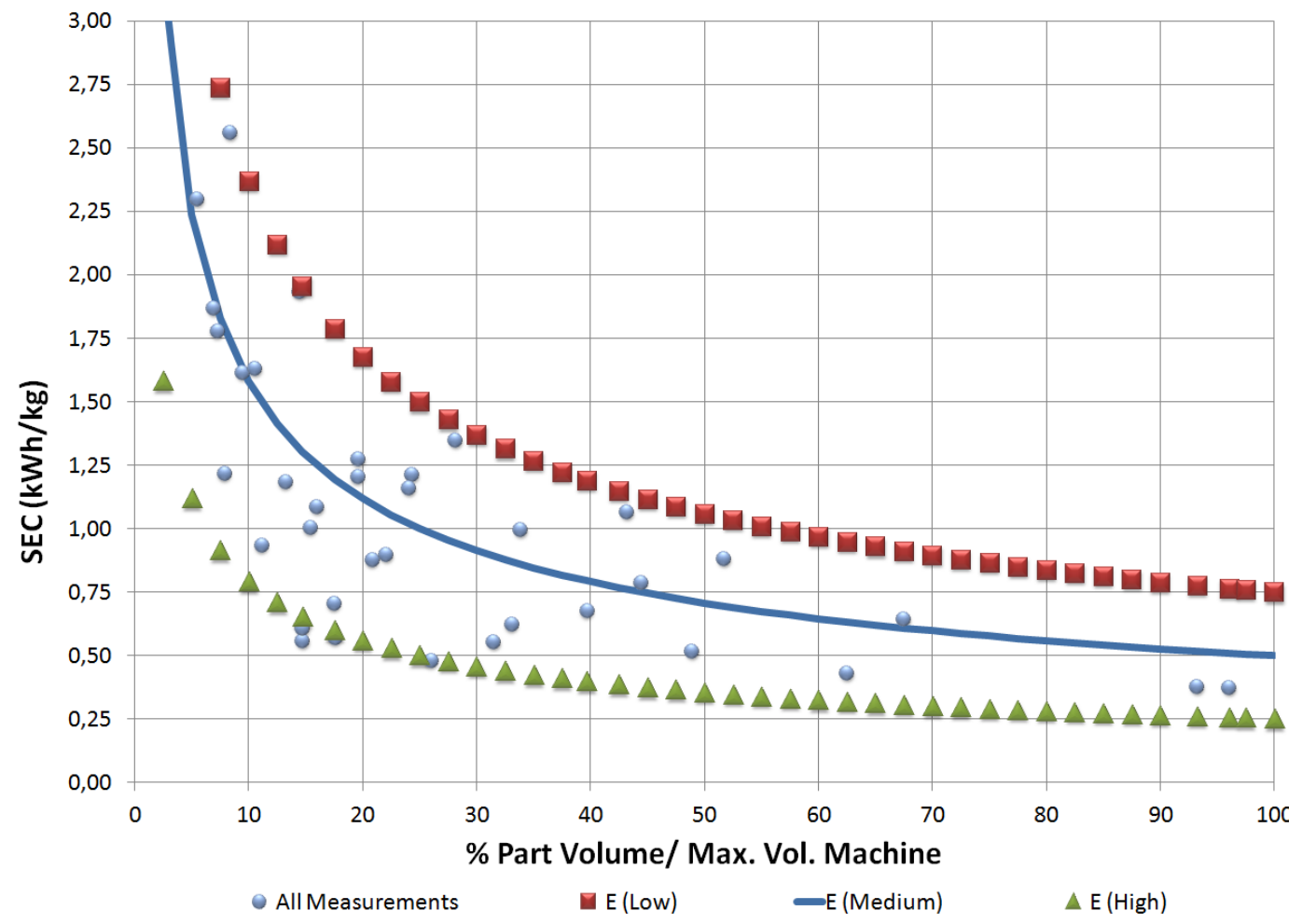

Figure 1. Empirical model.

Table 1 shows the electricity consumption values estimated by the model for the three cases shown in Figure 1, low efficiency machine, medium and high.

Table 1. Estimated electricity consumption in $\mathrm{KWh} / \mathrm{kg}$ for different values of machine efficiency and \% of utilization.

\begin{tabular}{cccc}
\hline \% of utilization & Low Efficiency & Medium Efficiency & High Efficiency \\
\hline 0 & 6,000 & 5,000 & 4,000 \\
10 & 2,372 & 1,581 & 0,791 \\
20 & 1,677 & 1,118 & 0,559 \\
30 & 1,369 & 0,913 & 0,456 \\
40 & 1,186 & 0,791 & 0,395 \\
50 & 1,061 & 0,707 & 0,354 \\
60 & 0,968 & 0,645 & 0,323 \\
70 & 0,896 & 0,598 & 0,299 \\
80 & 0,839 & 0,559 & 0,280 \\
90 & 0,791 & 0,527 & 0,264 \\
100 & 0,750 & 0,500 & 0,250 \\
\hline
\end{tabular}

Values from Table 1 are obtained with Equation 1:

$$
\operatorname{SEC}(\mathrm{KWh} / \mathrm{kg})=(7,5-5 \cdot \mathrm{E} / 100) \cdot(\eta)^{0,5}
$$

where $\mathrm{E}$ is the efficiency of the injection machine, and $\eta$, the percentage of utilization of the injection molding machine. $\eta$ is defined as Equation 2 indicates:

$$
\eta=w \cdot 100 / \rho . V_{\max }
$$


where $\mathrm{w}$ is the part's weight in grams, $\rho$ is the density of the polymer material $\left(\mathrm{g} / \mathrm{cm}^{3}\right)$ and $\mathrm{V}_{\max }$ is the maximum value that the injection molding machine is able to inject $\left(\mathrm{cm}^{3}\right)$.

Value for $0 \%$ of utilization is included as a reference, as it cannot be infinite.

In this second step, a better adjustment is obtained modifying the considered efficiency with two correction factors. The first one is related with the throughput of the process. A higher throughput will lead to a more optimized process (higher value of efficiency and lower electricity consumption). An empirical value has been calculated to estimate the average throughput depending on the clamping force of the injection molding machine (Equation 3).

$$
\text { Average Throughput }(\mathrm{kg} / \mathrm{h})=0,051 \text {. Clamping Force (Tonnes) }
$$

This way the correction factor of the throughput (CFT) will be defined as (Equation 4):

$$
\mathrm{CFT}=\left(\mathrm{w} \cdot 3,6 / \mathrm{t}_{\mathrm{c}}\right) / 0,051 . \mathrm{F}_{\mathrm{c}} \text { (Tonnes) }
$$

being $t_{c}$, the cycle time in seconds.

In Equation 5 is defined the second factor that adds the influence of the polymer material (CFP).

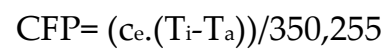

Using the specific heat of the polymer material $\left(\mathrm{ce}_{\mathrm{e}}\right)$ and the difference between injection temperature $\left(\mathrm{T}_{\mathrm{i}}\right)$ and ambient temperature $\left(\mathrm{T}_{\mathrm{a}}\right)$. The " 350,255 " is an experimental value obtained as an average of the factor ce. $\left(T_{i}-T_{a}\right)$ in the measurements.

So, finally, the modified machine's efficiency, E', that replaces E in Equation 1, is defined including it in the model with Equation 6:

$$
\mathrm{E}^{\prime}=\mathrm{E} .(\mathrm{CFT})^{0,15} /(\mathrm{CFP})^{0,1}
$$

where the influence of the throughput is higher than the one of the polymer material.

The considered efficiency for each injection molding machine was selected considering their technology and manufacturing date as the Table 2 shows.

Table 2. Machine's efficiency for the empirical model, E.

\begin{tabular}{cccc}
\hline $\begin{array}{c}\text { Injection Molding } \\
\text { Machine }\end{array}$ & Clamping force (Tn) & Manufacturing date & Efficiency (E) \\
\hline A & 8000 & 2005 & 70 \\
B & 5200 & 2005 & 70 \\
C & 3000 & 2000 & 65 \\
D & 2000 & 2010 & 75 \\
E & 1650 & 2010 & 75 \\
F & 1200 & 1999 & 65 \\
G & 1000 & 2008 & 70 \\
H & 750 & 2005 & 70 \\
I & 400 & 1996 & 60 \\
J & 200 & 1999 & 65 \\
K & 125 & 1999 & 65 \\
L & 85 (All-electric) & 2002 & 100 \\
\hline
\end{tabular}


Taking all this into account, the final equation of the empirical model is shown in Equation 7:

$$
\mathrm{SEC}=\left(7,5-\left(5 \cdot(\mathrm{E} / 100) \cdot\left(\left(\left(\mathrm{w} \cdot 3,6 / \mathrm{t}_{\mathrm{c}}\right) /\left(0.051 \cdot \mathrm{F}_{\mathrm{c}}\right)\right)^{0,15} /\left(\mathrm{Ce}_{\mathrm{e}}\left(\mathrm{T}_{\mathrm{i}}-\mathrm{T}_{\mathrm{a}}\right) / 350,255\right)^{0,1}\right)\right)\right) \cdot\left(\mathrm{w} \cdot 100 /\left(\rho \cdot \mathrm{V}_{\max }\right)\right)^{0,5}
$$

In Figure 2, the model's results are displayed comparing real measurement data with the estimation of the empirical model and the EcoInvent's value for the electricity consumption of the injection molding process for $1 \mathrm{~kg}$ of thermoplastic.

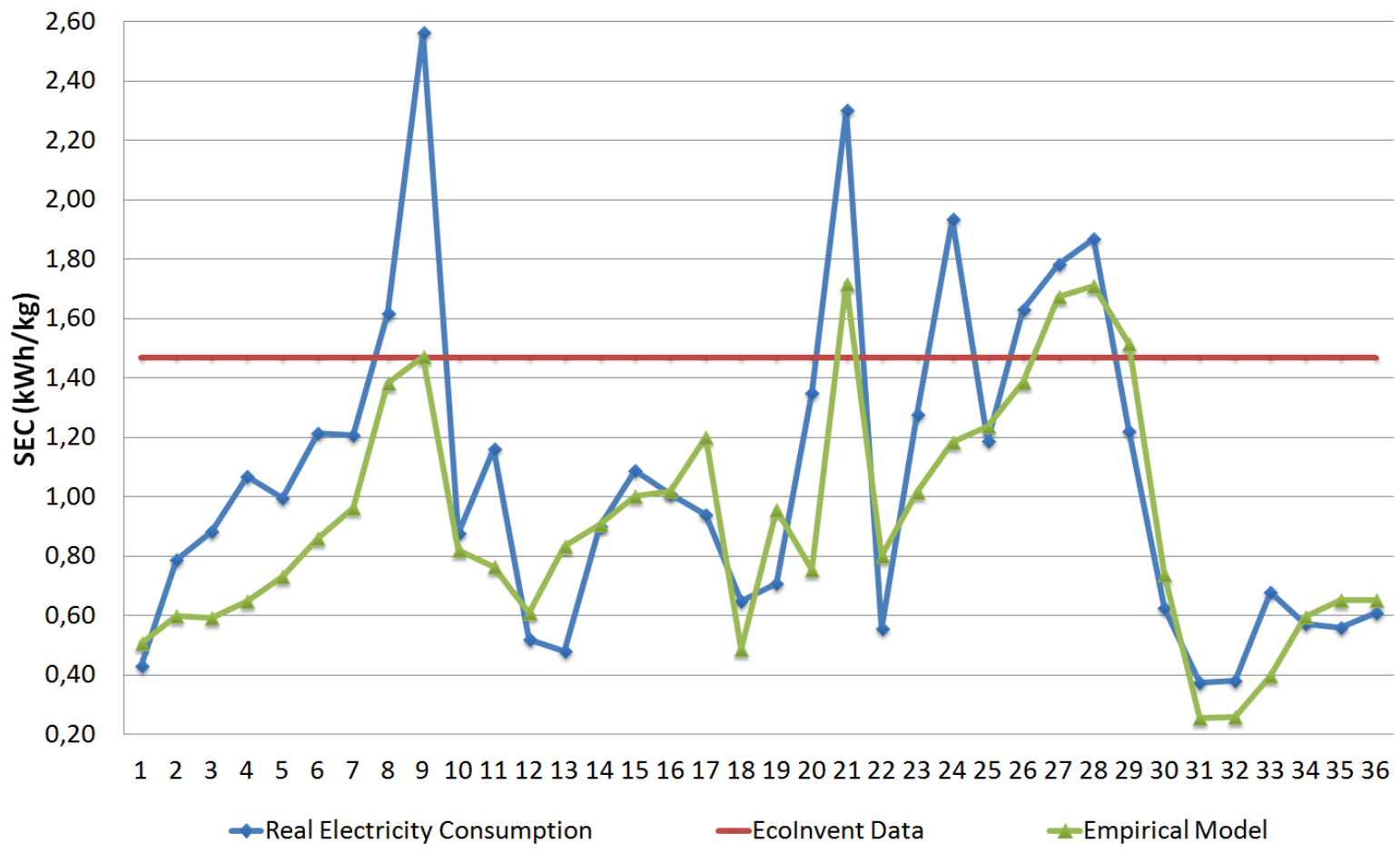

Figure 2. Comparison of Model's results, real data values and EcoInvent's.

An average of absolute error of a $22,5 \%$ is obtained with the empirical model lower than the $86,8 \%$ absolute error obtained using EcoInvent's value for this set of measured parts.

Part \#9 register the maximum error in this empiric model. This part was injected in one of the largest machines $(\mathrm{C})$, it has a high thickness and during its process it required a high cycle time for its processing which lead to a low $\mathrm{kg} / \mathrm{h}$ value. In addition, the $\eta$ is very low. As it can be seen in Figure 1 , for low values of utilization, the model's uncertainty increases, as the electric consumption result is much more sensitive to changes in E' value.

\section{Conclusions}

By using the proposed model in this paper, a better estimation of the electricity consumption can be achieved. Databases such as EcoInvent provide an average value for the injection molding process electricity consumption $(1,47 \mathrm{kWh} / \mathrm{kg})$. Considering this value as a constant of every injected molded part leads to an error due to that variability in this process is very high, as experimental measurements revealed depending on polymer material, injection molding machine and process's parameters. Our empirical model obtains an average absolute error of $22.5 \%$, much lower than the $86.8 \%$ obtained when using EcoInvent's data.

As future research directions, increase the number of experimental measurements with other injection molding machines with different clamping forces and technologies could help to improve the estimation obtained with the empirical model.

Also as each injection molding machine seem to have a unique profile of electricity consumption, to carry out a benchmarking of the plant machinery is an important step to be made by plastic producers and characterize correctly the machine's efficiency. 
Acknowledgments: This research work has been performed by members of the I+AITIIP (DGA-T08_17R) research group of the FEDER 2014-2020 "Construyendo Europa desde Aragón" program, recognized by the Regional Government of Aragon. No grants have been received to support this study.

Author Contributions: A.Elduque contributed to the study carrying out partially the experimental measurements shown in the study, reviewing the state of art, analyzing the experimental data to propose the empirical model and writing the paper, D.Elduque performed partly the experimental measurements, contributing to the adjustment of the model and revising the paper; I. Clavería and C Javierre. contributed to give structure to the paper, and adjust the empirical model analyzing the data and drawing conclusions.

Conflicts of Interest: The authors declare no conflict of interest.

\author{
Abbreviations \\ The following abbreviations are used in this manuscript: \\ CFP: Correction Factor of the Polymer material \\ CFT: Correction Factor of the Throughput \\ LCA: Life Cycle Assessment \\ SEC: Specific Electricity Consumption (unit in $\mathrm{kWh} / \mathrm{kg}$ )
}

\title{
References
}

1. Elijido-Ten, E.O.; Clarkson, P. Going Beyond Climate Change Risk Management: Insights from the World's Largest Most Sustainable Corporations. J Bus Ethics, 2017, 1-23, https://doi.org/10.1007/s10551017-3611-6.

2. Dornfeld, D. Moving towards Green and Sustainable Manufacturing. Int J. of Precis. Eng. Manuf.-Green Tech., 2014, 1, 63-66, https://doi.org/10.1007/s40684-014-0010-7.

3. European Parliament. Directive 2012/19/EU of the European Parliament and of the Council of 4 July 2012 on Waste Electrical and Electronic Equipment (WEEE); Official Journal of the European Union, EU Publications Office. 2012, Luxembourg. Available online URL: http://eur-lex.europa.eu/legalcontent/EN/TXT/?uri=CELEX:32012L0019.

4. European Parliament and the Council. Directive 2009/125/EC of the European Parliament and of the Council of 21 October 2009 Establishing a Framework for the Setting of Ecodesign Requirements for Energy-Related Products; Official Journal of the European Union, EU Publications Office: Brussels. 2009 , Belgium. Available online URL: https://eur-lex.europa.eu/legalcontent/EN/ALL/?uri=celex\%3A32009L0125.

5. Correa, M.; Pawlowsky, U.; Scurupa, K. Environmental performance evaluation - A proposed analytical tool for an industrial process application. J Clean Prod. 2018, 20, 1452-1464, https://doi.org/10.1016/j.jclepro.2017.10.289.

6. Cheung, W. M.; Leong, J. T.; Vichare, P. Incorporating lean thinking and life cycle assessment to reduce environmental impacts of plastic injection moulded products. J Clean Prod. 2017, 167, 759-775, https://doi.org/10.1016/j.jclepro.2017.08.208.

7. International Standard Organization. ISO 14040:2006 Environmental Management-Life Cycle Assesment-Principles and Framework; International Standard Organization. 2006, Geneva, Switzerland.

8. International Standard Organization. ISO 14044:2006 Environmental Management-Life Cycle Assessment-Requirements and Guidelines; International Standard Organization: 2006, Geneva, Switzerland.

9. Kellens, K.; Dewulf, W.; Overcash, M.; Hauschild, M.Z.; Duflou, J.R. Methodology for systematic analysis and improvement of manufacturing unit process life-cycle inventory (UPLCI) -CO2PE! initiative (cooperative effort on process emissions in manufacturing). Part 1: Methodology description. Int. J. Life Cycle Assess. 2012, 17, 69-78, https://doi.org/10.1007/s11367-011-0340-4.

10. Kellens, K.; Dewulf, W.; Overcash, M.; Hauschild, M.Z.; Duflou, J.R. Methodology for systematic analysis and improvement of manufacturing unit process life cycle inventory (UPLCI) CO2PE! initiative 
(cooperative effort on process emissions in manufacturing). Part 2: case studies. Int. J. Life Cycle Assess. 2012, 17, 242-251, https://doi.org/10.1007/s11367-011-0352-0.

11. Kellens, K.; Dewulf, W.; Lauwers, B.; Kruth, J.; Duflou, J. Environmental Impact Reduction in Discrete Manufacturing: Examples for Non-Conventional Processes. Procedia CIRP 2013, 6, 27-34, https://doi.org/10.1016/j.procir.2013.03.003.

12. Duflou, J.R.; Kellens, K.; Renaldi, R.; Guo, Y.; Dewulf, W. Critical comparison of methods to determine the energy input for discrete manufacturing processes. CIRP Ann.-Manuf. Technol. 2012, 61, 63-66, https://doi.org/10.1016/j.cirp.2012.03.025.

13. Duflou, J.R.; Sutherland, J.W.; Dornfeld, D.; Herrmann, C.; Jeswiet, J.; Kara, S.; Hauschild, M.; Kellens, K. Towards energy and resource efficient manufacturing: A processes and systems approach. CIRP Ann.-Manuf. Technol. 2012, 61, 587-609, https://doi.org/10.1016/j.cirp.2012.05.002.

14. PlasticsEurope, Association of Plastic Manufacturers. Plastics- the Facts 2017, An analysis of European plastics production, demand and waste data. 2018 , Brussels. Available online URL: https://www.plasticseurope.org/en/resources/publications/274-plastics-facts-2017

15. Elduque, A., Javierre, C., Elduque, D. and Fernández, Á. LCI Databases Sensitivity Analysis of the Environmental Impact of the Injection Molding Process. Sustainability, 2015, 7, 3792-3800, http://www.mdpi.com/2071-1050/7/4/3792.

16. Elduque, A., Elduque, D., Javierre, C., Fernández, Á. and Santolaria, J., Environmental impact analysis of the injection molding process: analysis of the processing of high-density polyethylene parts. J Clean Prod, 2015, 108, 80-89, https://doi.org/10.1016/j.jclepro.2015.07.119.

17. Medeiros, D.L.; Tavares, A.O..C.; Rapôso, Á.L.Q.; Rapôso,S.; Kiperstok, A. Life cycle assessment in the furniture industry: the case study of an office cabinet. Int J Life Cycle Assess. 2017, 22, 1823-1836, https://doi.org/10.1007/s11367-017-1370-3.

18. Jiménez, E.; Martínez, E.; Blanco, J.; Pérez, M.; Graciano, C. Methodological approach towards sustainability by integration of environmental impact in production system models through life cycle analysis: Application to the Rioja wine sector. SIMULATION, 2014, 90(2), 143-161, https://doi.org/10.1177/0037549712464409.

19. Finnegan, W.; Yan, M.; Holden, N.M.; Goggins, J. A review of environmental life cycle assessment studies examining cheese production. Int J Life Cycle Assess. 2017, 1-15, https://doi.org/10.1007/s11367017-1407-7.

20. Simone Souza, H.H.; Lima, Â.M.F.; Esquerre, K.O.; Kiperstok, A. Life cycle assessment of the environmental influence of wooden and concrete utility poles based on service lifetime. Int J Life Cycle Assess. 2017, 22, 2030-2041, https://doi.org/10.1007/s11367-017-1293-z.

21. Martínez, E.; Blanco, J.; Jiménez, E.; Saenz-Díez, J.; Sanz, F. Comparative evaluation of life cycle impact assessment software tools through a wind turbine case study. Renew. Energy 2015, 74, 237-246, https://doi.org/10.1016/j.renene.2014.08.004.

22. Tangsubkul, N.; Beavis, P.; Moore, S.; Lundie, S.; Waite, T. Life Cycle Assessment of Water Recycling Technology. Water Resour. Manag. 2005, 19, 521-537, https://doi.org/10.1007/s11269-0055602-0.

23. Modahl, I.S.; Askham, C.; Lyng, K.-A.; Brekke, A. Weighting of environmental trade-offs in CCS-an LCA case study of electricity from a fossil gas power plant with post-combustion CO2 capture, transport and storage. Int. J. Life Cycle Assess. 2012, 17, 932-943, https://doi.org/10.1007/s11367-0120421-z.

24. Hischier, R. Part II Plastics. Life Cycle Inventories of Packaging and Graphical Papers. Ecoinventreport № 11. Swiss Centre for Life Cycle Inventories, 2007, Dübendorf.

25. Boustead, I. Eco-Profiles of the European Plastics Industry. Polymer Conversion. Report 10; PlasticsEurope. 1997, Brussels, Belgium.

26. Plastics Europe. Eco-profiles of the European Plastics Industry. Injection Moulding of PVC, HDPE and PP; Plastics Europe. 2010, Brussels, Belgium.

27. Habersatter, K.; Fecker, I.; Dall'Acqua, S.; Fawer, M.; Fallscheer, F.; Förster, R.; Maillefer, C.; Ménard, M.; Reusser, L.; Som, C.; et al. Ökoinventare für Verpackungen; BUWAL Schriftenreihe Umwelt Nr 250; Bern Bundesamt für Umwelt, Wald und Landschaft (BUWAL). 1998, Bern, Switzerland. 
28. Mianehrow, H.; Abbasian, A. Energy monitoring of plastic injection molding process running with hydraulic injection molding machines. J Clean Prod. 2017, 148, 804-810, https://doi.org/10.1016/j.jclepro.2017.02.053.

29. Thiriez, A. An Environmental Analysis of Injection Molding. Master of Science in Mechanical Engineering. 2006, Massachussets Institute of Technology. Available online URL: http://hdl.handle.net/1721.1/35646.

30. Ribeiro, I.; Peças, P.; Henriques, E. A life cycle framework to support materials selection for Ecodesign: A case study on biodegradable polymers. Mater. Des. 2013, 51, 300-308, https://doi.org/10.1016/j.matdes.2013.04.043.

31. Almeida, D. Life Cycle Engineering approach to analyze the performance of biodegradable injection moulding plastics, 2011, Instituto Superior Técnico, Universidade Técnica de Lisboa.

32. Weissman, A.; Gupta, S. K.; Ananthanarayanan, A.; Sriram, R. D. A systematic methodology for accurate design-state estimation of energy consumption for injected molded parts. 2010, Montreal,Quebec.

33. Madan J.; Mani, M.; Lee, J.H.; Lyons K.W. Energy performance evaluation and improvement of unitmanufacturing processes: injection molding case study. J Clean Prod. 2015, 105, 157-170, https://doi.org/10.1016/j.jclepro.2014.09.060

34. Spiering, T.; Kohlitz, S.; Sundmaeker, H.; Herrmann, C. Energy efficiency benchmarking for injection moulding processes. Robot Cim- Int Manuf, 2015, 36, 45-59, https://doi.org/10.1016/j.rcim.2014.12.010

35. Abeykoon, C., Kelly, A.L., Vera-Sorroche, J., Brown, E.C., Coates, P.D., Deng, J., Price, M.. Process efficiency in polymer extrusion: correlation between the energy demand and melt thermal stability. Appl. Energy. 2014, 135, 560-571, https://doi.org/10.1016/j.apenergy.2014.08.086.

36. Abeykoon, C., Kelly, A.L., Brown, E.C., Vera-Sorroche, J., Coates, P.D., Harkin-Jones, E., Price, M. Investigation of the process energy demand in polymer extrusion: a brief review and an experimental study. Appl. Energy. 2014, 136, 726-737, https://doi.org/10.1016/j.apenergy.2014.09.024.

37. Elduque, A.; Elduque, D.; Clavería, I.; Javierre, C. Influence of Material and Injection Molding Machine's selection on the electricity consumption and environmental impact of the injection molding process: an experimental approach. Int. J. of Precis Eng. Manuf.-Green Tech. 2018, 5, 13-28, https://doi.org/10.1007/s40684-018-0002-0.

(C) 2018 by the authors; licensee MDPI, Basel, Switzerland. This article is an open access article distributed under the terms and conditions of the Creative Commons Attribution (CC BY) license (http://creativecommons.org/licenses/by/4.0/). 